\title{
Lean, Agile, Resilient, And Green Human Resource Management: The Impact On Organizational Innovation And Organizational Performance
}

\section{Nima Alipour}

University of Tehran College of Engineering

Salman Nazari-Shirkouhi ( $\nabla$ snnazari@ut.ac.ir)

University of Tehran College of Engineering https://orcid.org/0000-0001-6320-4607

\section{Mohamad Sadegh Sangari}

Ryerson University Ted Rogers School of Management

\section{Hadi Rezaei Vandchali}

University of Tasmania Australian Maritime College

\section{Research Article}

Keywords: Lean agile resilient green (LARG) paradigm, Human resource management, Organizational performance, Organizational innovation, Structural equation modeling

Posted Date: February 17th, 2022

DOI: https://doi.org/10.21203/rs.3.rs-1271764/v1

License: (9) This work is licensed under a Creative Commons Attribution 4.0 International License. Read Full License 


\section{Abstract}

There are four paradigms of lean, agile, resilient, and green (LARG) which can promote human resource culture to create novel ideas and increase performance in organizations. This study aims to conceptualize lean, agile, resilient, and green paradigms in human resource management (HRM) and investigates how different LARG HRM elements can affect organizational innovation and performance. In this way, a conceptual model for investigating the LARG concept in HRM is proposed. A new tool to measure lean, agile, resilient, and green indicators in service industry has been developed. Using convenience sampling method to access possible respondents, a survey questionnaire is managed to collect data from 102 service sector organizations in Iran. The collected data are analyzed by partial least squares-structural equation modeling (PLS-SEM). The results indicate that the LARG HRM significantly and positively influences organizational performance. In addition, the LARG HRM indirectly affects organizational performance through organizational innovation. This study provides valuable insights into implementing the LARG HRM in organizations and how it contributes to enhancing organizational performance.

\section{Introduction}

Nowadays, one of the main challenges for organizations is the presence of the right, talented and skilled human resource (HR) as it can determine the level of knowledge in their processes (Holtom et al. 2008), which play an essential role in achieving competitive advantages (da Silva César et al. 2019). Vaňová et al. (2019) demonstrated that talented and creative HR in both production and service-based organizations leads to sustainable development and competitive advantage through creating new economic values and increasing capabilities of attracting other high-quality HR. Production and servicebased organizations have different characteristics and work policies, particularly regarding human resources' behavior and interaction with customers. Service-based organizations should concentrate more on employees' behavior and service-based aspect to achieve their goals and success in competitive environments (Lu et al. 2015). Employees in service-based organizations create an image of these organizations in customers' minds due to their direct and continuous relations. The staff of service-based organizations presents the products of these organizations (services), and they are responsible for the quality of services in customers' views (Lu et al. 2015). Indeed, the customers' satisfaction of servicebased organizations depends greatly on their staff. Also, services are the non-separable part of each activity in each organization, and it is impossible to conceive an organization without services. In addition, the service sector is one of the most effective drivers of economic growth (Orhan et al. 2019) and one of the fastest-growing sectors in Iran due to the increasing internet services and social network usage in recent years. The service sector with an annual gross domestic product (GDP) growth rate of about 9\% from 2018 to 2019, had the largest share in Iran's GDP (CBI 2019).

One of the most critical problems of the modern world is the customers' belated attainment of their goals, i.e., lengthening of the service receiving response time. On the other hand, the ever-increasing rise in the prices of commodities, especially in Iran, has been transformed into a fundamental problem. However, a 
large bulk of this cost escalation is rooted in unnecessary affairs or extra transportation. Likewise, attention to environmental issues has been turned into a principle for organizations since their consideration can alter people's attitudes toward the respective organization (Mathapati 2013). Lean, agile, resilient, and green (LARG) paradigms are recognized as the foundations of competitiveness (Cabral at al. 2012). Therefore, managers should perform the LARG thinking to make organizations more competitive by quickly responding to customer needs, effectively reacting to unexpected events in line with their environmental responsibilities, and eliminating worthless and insignificant processes (Cabral et al. 2012).

The LARG concept was first introduced by Azevedo et al. (2010) in supply chain management (SCM). In today's competitive world, lean, agile, resilient, and green should not be used separately in the system, while a set of requirements and activities should be used simultaneously to increase efficiency, effectiveness, and competitiveness (Machado and Duarte 2010). Carvalho and Cruz-Machado (2011) argue that an organization following the requirements of lean, agile, resilient, and green strategies benefits from their advantages, and subsequently, their competitiveness may increase, and the existing conflicts between them will be eliminated. As a result, synergy occurs in a system.

Despite the importance of applying the LARG concept in HRM, there is a lack of empirical research on how these four paradigms can be simultaneously applied in HRM. Hence, this study attempts to propose a conceptual model for the LARG HRM with the interference of organizational innovation by using the structural equation modeling (SEM) method to analyze the influence level of variables when implementing the LARG concept in organizations. This study aims to develop a conceptual model for the LARG HRM and investigates how it affects organizational performance. The proposed model contributes to improve organizational performance and can be adopted by service-oriented organizations to achieve a high level of competitiveness.

The remainder of this study is organized as follows: Section 2 presents the research framework, provides a theoretical development of the LARG HRM, discusses the concepts of organizational innovation and organizational performance, and develops a set of hypotheses. Section 3 describes the methodology adopted for the study. The results of the measurement and structural model are explained in Section 4, followed by discussing the implications and limitations of the study in Section 5. Section 6 concludes the paper.

\section{Research Framework}

Fig. 1 presents the LARG HRM framework developed in this research by utilizing lean, agile, resilient, and green paradigms to investigate the impact of the LARG HRM on organizational performance and innovation. The proposed model used organizational innovation as a mediator variable to achieve organizational performance. The model proposes that the LARG HRM influences organizational performance both directly and indirectly through organizational innovation. The LARG HRM is divided into four paradigms: lean HRM, agile HRM, resilient HRM, and green HRM. Using literature support, the 
expected relationships among LARG HRM paradigms, organizational innovation, and organizational performance are discussed

\subsection{LARG HRM}

In recent years, a limited number of studies have focused on the simultaneous combination of lean, agile, resilient, and green strategies, which have been conducted in a few specific domains, including SCM and production (Azevedo et al. 2011; Cabral et al. 2012; Govindan et al. 2015; Rachid 2017; Raut et al. 2021; Salleh et al. 2020). The lean paradigm focuses on increasing productivity and quality, which can help managers reduce the organization's cost and improve the productivity and performance of the organization (Cabral et al. 2012). Organizations have found the importance of the lean paradigm in the operation management area and identified the significant impact of HRM strategies in their operation management (Bamber et al. 2014). The lean paradigm in HR indicates improving employees' productivity and performance by reducing the time wastage in their activities in organizations. To survive in an uncertain and unstable situation, organizations can consider the agile paradigm throughout their activities. Agility is the ability of organizations to manage changes in the market situations and respond to uncertainty (Gligor et al. 2015). Implementing agile thinking among employees can enhance their speed and flexibility, increase the quality of employees' activities, and lead to more productive operations (Lyskova and Rudakova 2020; Vilkas et al. 2019). The purpose of promoting agile thinking in HR is to enhance the staff's reaction to the changes. HR flexibility positively impacts the adaption culture and enhances the organization's innovation capability (Do et al. 2016). Ketkar and Sett (2009) stated that HR flexibilities intercede the effects of environmental mobility on organizational performance. They also found that HR practices, directly and indirectly, affect HR outcomes, which ultimately impact organizational performance. Before reacting to any instability, employees should learn to preserve the system in a balanced or normal mode. Organizations attempt to maintain the system in normal mode or improve their ability to recover the system in a normal situation

(Azadeh et al. 2014). Concerning HR, this paradigm addresses the enhancement of employees' awareness, flexibility, teamwork, learning, and reporting culture. Moreover, this paradigm helps employees to encounter issues more effectively, thus, affects organizational performance both directly and indirectly. The capabilities of organizational resilience highlight the vital role of HRM in improving organizational performance through developing HR practices (Kossek and Perrigino 2016). Currently, the green paradigm allows organizations to achieve economic goals, decrease environmental impacts, and improve ecological performance through various ways such as reducing and eliminating wastage, recycling, and saving energy (Chin et al. 2015; Khan and Qianli 2017; Zhu et al. 2008). Various works in the literature have emphasized the necessity of GHRM to support green management practices, by discussing the positive effects of HR on organizational performance (Amjad et al. 2021; Paauwe and Boselie 2005; Schuler and Jackson 2014). Organizations should employ their staff emphasizing eco-friendly behavior and commitment to green thinking. HR with green thinking in an organization can lead to the development of green culture reaching high ecological performance by highlighting the importance of green policies followed by organizations' employees (Alipour et al. 2019). Ahmad (2015) focused on green HRM (GHRM) practices and highlighted that GHRM includes policies to create a balance between the environment, society, and economic aspects. The LARG 
concept contains all four paradigms of lean, agile, resilient, and green simultaneously. The LARG concept is a new social-technical system that helps organizations' employees to reduce wastes and improve productivity. Also, it helps HR to be more flexible and provide an effective and quick response to changing customers' behavior, and to support environmental management by decreasing environmental risks at the same time (Cabral et al. 2012). Hence, by utilizing the LARG HRM concept, organizations can reduce their costs, wastes, and environmental issues as well as improving their performance. Furthermore, the implementation of the LARG HRM thinking enables organizations to deal with sudden changes effectively and quickly, and to improve the stability of the system.

\section{2 organizational innovation}

The growing concern over the importance of organizational innovation as a driver of competitiveness in a dynamic environment and its close relationship with financial growth leads organizations toward focusing on this concept. According to the definitions, innovation means implementing novel ideas and thoughts resulting from creativity (Azeem et al. 2021). The result of this process in service-based organizations can be a service or a new procedure with improved features and usages that can ultimately improve organizational performance and create values for their shareholders (Henard and Szymanski 2001). It also is a process in which these organizations can detect the existing problems and challenges, and then utilize the novel knowledge to solve them (Du Plessis 2007). Organizations having the capacity to create innovation can better respond to continuous environmental changes and challenges and adapt themselves to environmental evolutions (Lee and Hsieh 2010). The effects of innovation in the processes

of an organization can be assessed through some criteria such as removing redundant activities in the service provision process, reducing variable costs, and increasing delivery speed (Shaukat et al. 2013). By definition, considering organizational innovation can help HR to find creative ways to implement lean, agile, resilient, and green paradigms and innovative organizations can act successfully in implementing the LARG concept.

\section{3 organizational performance}

The success and survival of an organization depend on its performance. Organizational performance is an effective index for organizations to measure their success in reaching their objectives ( $\mathrm{Li}$ et al. 2006; Rehman et al. 2019). Performance measurement is amply important since it monitors the system performance and reveals how organizational strategies are implemented (Chenhall 1997). Parker et al. (2000). believe that performance measurement plays a significant role in improving quality and productivity for the reasons below:

- It assures that customer needs and requirements are supplied.

- It establishes standards for comparing, leading, and planning.

- It bolds quality problems and specifies the areas that need specific attention.

- It shows the costs resultant from quality non-observance.

- It regulates the use of resources. 
- It assures that decisions are based on reality, not assumptions and feelings.

By measuring the organizational performance, managers, investors and stakeholders can understand how well their organizations are competing in the market, as well as future predicted results.

\subsection{Research hypotheses}

Innovative organizations always seek the best and effective way to manage their staff to implement the innovation concept, create new products, and provide better service (Ostraszewska et al. 2019). Skibiński and Sipa (2015) indicated that improving the knowledge of employees and converting them into highskilled employees can be the source of ideas for new products and services. Organizations need to have employees who are highly participating and involving in the assigned tasks (Mak and Akhtar 2003). Organizations need innovative HR, with flexibility and risk-taking characteristics to develop innovations, including introducing new products, services, and new processes (Chen et al. 2007). Addressing an innovation strategy requires organizations to have creative, skillful, and innovative HR, who have no problems with uncertain situations and take responsibilities to work independently (Jimenez-Jimenez and Sanz-Valle 2008). According to Agarwala ( 2003), organizations should continuously modify their HRM practices based on the changes in the situations. Jimenez-Jimenez and Sanz-Valle (2005) emphasized that adopting effective HRM practices significantly explains the organization's innovation orientation. Organizations should highly focus on the selection of supportive HRM practices to encourage employees to be innovative. Effective HRM practices motivate staff to bring up new ideas, share their knowledge with others, and implement changes resulting in organizational innovation. Thus, implementation of the LARG HRM thinking in organizations can increase their HR responsibilities and encourage them to work independently which motivates staff to encounter problems and issues in uncertain situations quickly. Hence, the following hypothesis is presented:

Hypothesis 1. LARG HRM has a positive effect on organizational innovation.

Increasing organizational performance is regarded as one of the most important targets of HRM (Guest et al. 2012). To achieve a competitive advantage, organizations should use HRM effectively, and their staff plays a critical role in this way (Jimenez-Jimenez and Sanz-Valle 2008). In recent years, a large body of research has addressed the relationship between HRM and organizational performance (Correa and Craft 1999; Khatri 2000; Yu et al. 2013). Given the lack of a precise definition for organizational performance, Guest (1997) suggested using the "outcome" concept instead of performance and categorizing it into the financial, organizational, and HR outcomes. Maheshwari and Vohra (2015) demonstrated the high connection between HR and organizational outcome, meaning that this part of the outcome is closer to HR practices in organizations. Al-Najjar (2010) found that promoting the knowledge of HR can significantly affect the performance of organizations, especially from the financial perspective (Safkaur and Sagrim 2019). Lambooij et al. (2006) investigated the relationship between HRM and organizational performance and found that HRM generally affects performance and allows organizations to have more productive employees and better performance. Using the LARG concept in HRM can help organizations have more productive staff and effectively enhance their performance. In addition, it can significantly 
affect HR flexibility, quality, and reactions in unpredictable situations. The resilience factors, including HR awareness, teamwork, learning, and reporting culture, would also be improved by implementing the LARG concept. It also decreases environmental impacts and increases personnel commitments helping organizations to achieve higher ecological performance. Therefore, the following hypothesis is derived:

\section{Hypothesis 2. LARG HRM has a positive effect on organizational performance.}

Various studies have been carried out in the last few years on the relationship between organizational innovation and organizational performance (Al-Hakim and Hassan 2013a; Gunday et al. 2011; Uzkurt et al. 2013). Jimenez-Jimenez and Sanz-Valle (2008) concluded that considering innovation in an organization can simultaneously reduce costs and improve quality. Consequently, by adopting innovation, organizations can improve their productivity and the quality of products or services. Innovative thinking in an organization enables HR to be more creative which can improve the organizational performance (Su et al. 2018). The results of innovation in products/services and processes help organizations to have innovative behavior, which usually originates from organizational capacities (Prajogo and Ahmed 2006). Camisón (1999) analyzed the innovative behavior of organizations and their response to demands and demonstrated that this behavior provides the ability to achieve better entrepreneurial results. Organizational innovation is a vital factor in the long-term success of organizations. This factor can help organizations increase their profits (Jiménez and Valle 2006). By concentrating on innovation, organizations can gain more market share and higher income. In other words, organizational innovation is essential for gaining better performance (Chen et al. 2020; GarcíaMorales et al. 2008). Therefore, we present the following hypothesis:

\section{Hypothesis 3. Organizational innovation has a positive effect on organizational performance.}

\section{Research Methodology}

\subsection{Sample and participants}

The survey data for the present study were collected by a questionnaire from service-based organizations with front-end employees in Iran. The questionnaire respondents were selected from organizations with more than 50 employees (one per organization). The respondents consisted of 210 organizational experts, senior experts, and managers with a minimum experience of three years. The service industries from which the questionnaires were collected were as follows: banking and financial services $(32.3 \%)$; transportation (13.7\%); hotel (16.7\%); telecom (8.8\%); and insurance $(28.4 \%)$. The questionnaire included two parts of respondents' demographic characteristics (age, gender, education level, and position) and the items related to the factors and paradigms of the proposed model. The convenience sampling method was used to access possible respondents (Constantiou 2009). As one of the non-probability sampling methods, this method can decrease the cost and time of the data collection process (Mosavi et al. 2018). Questionnaires were distributed among respondents in a form of an online questionnaire (giving the questionnaire URL). Also, various ways such as personal visits, phone calls, and e-mail 
reminders were used to increase the participation rate. In total, 127 questionnaires were returned, and among 127 collected questionnaires, 25 incomplete questionnaires included missing data, and thus, only 102 questionnaires were usable. The valid response rate was $48.6 \%$. The respondents' demographic characteristics are reported in Table 1.

Table 1

Respondents' demographic characteristics

\begin{tabular}{|lll|}
\hline Information & Frequency & Percentage (\%) \\
\hline Gender & 87 & 85.3 \\
Male & 15 & 14.7 \\
\hline Age (years) & & \\
$20-30$ & 8 & 7.8 \\
$31-35$ & 37 & 36.3 \\
$>35$ & 57 & 55.9 \\
Highest educational level & 11 & 10.8 \\
Diploma and associate & 71 & 69.6 \\
Bachelor & 18 & 17.6 \\
Master & 2 & 2 \\
Doctorate & & \\
\hline Organizational position & 78 & 76.5 \\
Organizational expert & 12 & 11.8 \\
Senior expert & 12 & 11.8 \\
Manager & & 20.6 \\
\hline Total work experience (years) & 11 & 10.8 \\
$<6$ & 21 & 20.6 \\
$6-10$ & 26 & \\
$11-15$ & & \\
$>15$ & & \\
\hline
\end{tabular}

\subsection{Measurement}

Due to few studies that have been conducted in the lean, agile, resilient, and green in the HRM area, the measurement items were extracted from studies investigating these paradigms in the domains of 
production and SCM. Since we distributed the questionnaire between non-English respondents, we translated the English version of the evaluating items into Persian. The translated items were checked by several experts who had professional experience in the field. Then, the translated items were translated to English and compared with the original English items in terms of equality, and the validity and clarity of the final questionnaire were confirmed. Then, a pilot study was implemented with almost 40 managers of organizations to ensure the validity and reliability of the questionnaire items.

The items used in the questionnaire of this study consisted of six parts of lean HRM, agile HRM, resilient HRM, green HRM, organizational innovation, and organizational performance. The lean HRM was measured using five items developed by Nawanir et al. (2018), and the agile HRM was measured using five items developed by Sharifi and Zhang (1999). The resilient HRM was measured using five items developed by Azadeh et al. (2018) and Bardoel et al. (2014), and the green HRM was measured using four items developed by Hsiao et al. (2014). Organizational innovation and performance were measured using five items developed by Chen et al. (2016), and 12 items developed by Maletič et al. (2014), respectively. The survey items are listed in Appendix A. All the items were measured using a five-point Likert scale ( 1 , completely disagree; 2 , slightly disagree; 3 , neither agree nor disagree; 4 , slightly agree; 5 , completely agree).

\section{Results}

\subsection{Results for the measurement model}

\subsubsection{Convergent and discriminant validity}

The model in Fig. 1 was analyzed through PLS-SEM using SmartPLS software. To test the homogeneity of the measurement model, a factor analysis was conducted for the LARG HRM model using 36 items in six dimensions. If the absolute value of the factor loading between the observed variable and the related latent variable is at least 0.7, the measurement model will be homogeneous (Nunnally 1978). In addition, if this increases the composite reliability of the measurement model, it would be better to eliminate observed reflective variables with a factor loading of less than 0.4 (Temme et al. 2010). The results of the research show that in all hypotheses, the factor loading values are higher than the acceptable level. The results shown in Table 2 indicate that item (question) number 1, "Easy access of staff to the demanded facilities" had the highest factor of 0.602 and item (question) number 18, "perception of the staff about environmental policies of the organization" had the lowest factor of 0.883 . All the factor loading values, means, and standard deviations are shown in Table 2.

\subsubsection{Assessing reliability}

The reliabilities of the LARG HRM (lean HRM, agile HRM, resilient HRM, and green HRM), organizational innovation, and organizational performance were evaluated with Cronbach's Alpha. In the present study, Cronbach's alpha of all variables was higher than 0.7, which is considered acceptable (Lee et al. 2011). In 
the next step, we also analyzed the correlations for each of the constructs. All the correlations are significant at the $.01{ }^{(*)}$ ) and the $0.05\left(^{*}\right)$ levels.

\subsubsection{Internal consistency}

The internal consistencies of measurement items were assessed by the average variance extracted (AVE) and the composite reliability (CR). According to Fornell and Larcker (1981), this index shows the correlation between a variable and the items that explain it. The results of this test show that this index was above 0.5 in all variables, and the internal consistency of the first-order measurement model is acceptable (Davadas and Lay 2017). Table 3 also reports the results of the AVE test. Further, the CR test, which estimates the internal consistency of latent variables, was conducted between the factors of the conceptual model. The results of the CR test ranged from 0.832 to 0.922 , exceeding the recommended value of 0.7 (Hair et al. 2010; Sangari and Razmi 2015) indicate favorable stability of the internal latent variables. The results of reliability and consistency are reported in Table 3.

Table 2. Factor analysis, means, standard deviations 


\begin{tabular}{|c|c|c|c|}
\hline Factors \& items & Means & Standard deviations & Items loadings \\
\hline Lean & 3.88 & 0.596 & \\
\hline Lean 1 & 4.14 & 0.944 & 0.617 \\
\hline Lean 2 & 4.01 & 0.928 & 0.707 \\
\hline Lean 3 & 4.25 & 0.875 & 0.863 \\
\hline Lean 4 & 4.27 & 0.773 & 0.723 \\
\hline Lean 5 & 3.33 & 0.978 & 0.602 \\
\hline Agile & 3.64 & 0.807 & \\
\hline Agile 1 & 3.51 & 1.13 & 0.854 \\
\hline Agile 2 & 3.45 & 1.02 & 0.786 \\
\hline Agile 3 & 3.71 & 0.981 & 0.665 \\
\hline Agile 4 & 3.82 & 1.075 & 0.724 \\
\hline Agile 5 & 3.74 & 1.071 & 0.751 \\
\hline Resilient & 3.47 & 0.691 & \\
\hline Resilient 1 & 4.04 & 0.889 & 0.603 \\
\hline Resilient 2 & 3.39 & 0.924 & 0.707 \\
\hline Resilient 3 & 3.51 & 1.088 & 0.849 \\
\hline Resilient 4 & 2.85 & 1.112 & 0.745 \\
\hline Resilient 5 & 3.29 & 1.113 & 0.752 \\
\hline Green & 3.35 & 0.832 & \\
\hline Green 1 & 3.32 & 1.064 & 0.830 \\
\hline Green 2 & 3.13 & 1.087 & 0.857 \\
\hline Green 3 & 3.29 & 0.929 & 0.883 \\
\hline Green 4 & 3.64 & 0.888 & 0.779 \\
\hline Innovation & 3.65 & 0.658 & \\
\hline Innovation 1 & 3.78 & 0.961 & 0.681 \\
\hline Innovation 2 & 3.87 & 0.886 & 0.692 \\
\hline Innovation 3 & 3.74 & 0.795 & 0.622 \\
\hline Innovation 4 & 3.76 & 0.892 & 0.630 \\
\hline Innovation 5 & 3.47 & 0.972 & 0.773 \\
\hline Innovation 6 & 3.27 & 1.064 & 0.617 \\
\hline Performance & 3.61 & 0.634 & \\
\hline Performance 1 & 3.77 & 0.984 & 0.705 \\
\hline Performance 2 & 3.66 & 1.067 & 0.822 \\
\hline Performance 3 & 3.64 & 0.963 & 0.771 \\
\hline Performance 4 & 3.68 & 1.064 & 0.827 \\
\hline Performance 5 & 3.74 & 0.954 & 0.680 \\
\hline Performance 6 & 3.93 & 0.904 & 0.670 \\
\hline Performance 7 & 3.79 & 0.905 & 0.657 \\
\hline Performance 8 & 3.74 & 0.964 & 0.791 \\
\hline Performance 9 & 3.07 & 1.119 & 0.670 \\
\hline Performance 10 & 3.42 & 1.189 & 0.661 \\
\hline Performance 11 & 3.84 & 0.952 & 0.720 \\
\hline
\end{tabular}


Table 3

Cronbach's Alphas, AVEs, CRs, and correlations of variables

\begin{tabular}{|lllllllll|}
\hline Variables & Cronbach's a & AVE & CR & $\mathbf{1}$ & $\mathbf{2}$ & $\mathbf{3}$ & $\mathbf{4}$ & $\mathbf{5}$ \\
\hline 1. Lean & 0.748 & 0.502 & 0.832 & - & & & & \\
\hline 2. Agile & 0.813 & 0.576 & 0.871 & $0.680^{* *}$ & - & & & \\
\hline 3. Resilient & 0.786 & 0.541 & 0.854 & $0.506^{* *}$ & $0.619^{*}$ & - & & \\
\hline 4. Green & 0.859 & 0.702 & 0.904 & $0.514^{* *}$ & $0.670^{* *}$ & $0.617^{*}$ & - & \\
\hline 5. Innovation & 0.798 & 0.530 & 0.851 & $0.350^{* *}$ & $0.508^{* *}$ & $0.239^{* *}$ & $0.485^{* *}$ & - \\
\hline 6. Performance & 0.914 & 0.500 & 0.922 & $0.364^{* *}$ & $0.439^{* *}$ & $0.348^{* *}$ & $0.559^{* *}$ & $0.440^{*}$ \\
\hline *Correlation is significant at the .05 level. & & & & & & \\
\hline
\end{tabular}

$* *$ Correlation is significant at the .01 level.

\subsubsection{Validation of second-order constructs}

According to the conceptual model, lean, agile, resilient, and green HRM paradigms and organizational innovation and organizational performance are the first-order constructs. However, lean, agile, resilient, and green HRM variables are influenced by a fundamental variable called the LARG HRM. The LARG HRM is the second-order variable of the model. The reliability and validity of the second-order variable were assessed by Cronbach's Alphas, AVE, CR, and the results of these tests are shown in Table 4. According to the results, the reliability and the validity of the second-order variable were confirmed.

Table 4

Cronbach's Alpha, AVE, and CR of second-order

variable

\begin{tabular}{|llll|}
\hline Variable & Cronbach's a & AVE & CR \\
\hline LARG HRM & 0.907 & 0.590 & 0.921 \\
\hline
\end{tabular}

\subsection{Results for the structural model}

The relationships between independent latent variables (exogenous) and dependent variables (endogenous) are detailed. Therefore, after confirming the reliability and validity of measuring instruments, the next step analyzes and confirms the structural model. In this analysis, the size, sign, and significance level of the path coefficients should be examined. Greater coefficients indicate stronger relationships between two variables, and the negative coefficient will also indicate the inverse relationship between the variables (Henseler et al. 2009). The significance of these coefficients is also one of the essential parameters to confirm the structural model, which completes the size and sign of the beta 
coefficients in the model. The hypothesis is confirmed if this statistic is within the range of the level of confidence intended for it (Hair et al. 2011; Henseler et al. 2009). The results of path analysis are shown in Fig. 2 and Fig. 3. As shown in Fig. 2 and Fig. 3, the LARG HRM was supported very effectively by each of the four lean, agile, resilient, and green paradigms. Specifically, The LARG HRM relates to organizational innovation significantly and positively, which supports hypothesis 1 . The LARG HRM had a positive and significant effect on organizational performance. Additionally, organizational innovation positively and significantly affects organizational performance, which confirms hypotheses 2 and 3 . Table 5reports the results of this analysis.

Table 5

Results of path analysis

\begin{tabular}{|llll|}
\hline Path & $\begin{array}{l}\text { Path } \\
\text { coefficient }\end{array}$ & $\begin{array}{l}\text { t- } \\
\text { value }\end{array}$ & Supported \\
\hline H1: LARG HRM $\rightarrow$ Organizational innovation & 0.567 & 9.690 & Yes \\
\hline H2: LARG HRM $\rightarrow$ Organizational performance & 0.362 & 2.977 & Yes \\
$\begin{array}{l}\text { H3: Organizational innovation } \rightarrow \text { Organizational } \\
\text { performance }\end{array}$ & 0.278 & 2.618 & Yes \\
\hline Note: All the relationships are significant at $\mathrm{a}<.01$. & & & \\
\hline
\end{tabular}

The conceptual model of the present study shows that the LARG HRM not only directly affects the organization's performance but also indirectly affects the performance by encouraging organizational innovation. According to Table 5 and Fig. 2 , the direct effect was 0.362 , while the indirect effect was 0.160 . The total effect of the LARG HRM variable on organizational performance is 0.522 .

In the SEM method, the Goodness-of-fit (GOF) index was used for fitting the model. Totally, three values were obtained for this index (Small=0.1, Medium=0.25, Large= 0.36) (Birmingham et al. 2017). The coefficient $\mathrm{R}^{2}$ indicates the data support level of the conceptual model (Nikbin et al. 2016). The following equation was used to calculate this index for the proposed model (Henseler and Sarstedt 2013):

$$
G O F=\sqrt{\text { GQmmunality }} \times \sqrt{\mathbb{R}^{2}}
$$

In this study, R2, communality, and GOF index values were $0.478,0.534$, and 0.509 , respectively, indicating the desired rate of the fitting process in the proposed model.

\subsubsection{Mediator variable effect}

To test the mediation effect of organizational innovation in the conceptual model, the Sobel test was used. This test uses equation 2 such that if the Z-value is significant, then the mediator variable plays a significant role in the model (Hu et al. 2017). Considering the results of the Sobel test, the Z-value was obtained 2.527, which shows the significant effect of the mediator (organizational innovation). In models 
with a partial mediator variable, calculating that part of the indirect effects of the independent variable on the dependent variable is conducted through the Variance Accounted For (VAF) indicator (Temme et al. 2010). The partial mediator variable in this study is "organizational innovation". The value obtained for this indicator is 0.304 , which indicates the relatively medium impact of this variable (organizational innovation). In other words, organizational innovation can justify more than $30 \%$ of changes in organizational performance.

\section{Research Implications And Limitations}

This study reveals how lean, agile, resilient, and green paradigms can play a critical role in implementing the LARG thinking in the organizations' HRM. As shown in the previous section, all four paradigms significantly and positively affect the LARG HRM and can assist managers in organizations to realize the LARG concept and effectively apply it in HRM to achieve higher performance. Considering the significant and positive relationship between the LARG HRM and organizational innovation, it can be argued that applying the LARG thinking in HRM can significantly affect innovativeness, which was supported by previous studies (e.g., Fay et al. 2015; Jiang et al. 2012). Implementation of the LARG HRM in servicebased organizations can increase HR accessibility to the necessary knowledge and encourage senior managers to pay attention to employees' creativeness. It can lead to innovative methods in performing tasks and motivate the introduction of new services. Furthermore, applying the LARG concept in HRM develops methods to create new systems for strategic planning, employees' training, and promotion. Accordingly, the LARG concept plays a significant role in HR creativity and their growth and causes to recognize new markets constantly.

Our findings also support the significant and positive relationship between the LARG HRM and organizational performance, which was also confirmed by previous studies (e.g., Katou 2012, 2015, 2017). Organizations should focus on their staff to reach a higher organizational performance. As mentioned before, the LARG HRM leads organizations to have highly productive and innovative employees who can expand the market by developing new methods and services. This market expansion can benefit organizations from the customer side, which significantly improves organizations' performance.

The results of this study have also confirmed the significant and positive relationship between organizational innovation and organizational performance. Due to the presence of creative, skilled, welltrained, and promoted employees and novel systems for strategic planning, organizations can develop effective methods and processes offering new services to their customers. Subsequently, it results in increasing organizations' liquidity absorption, overall asset, profit, and improving performance. This finding highlights the necessity of supporting innovation by organizations in today's competitive world which has been verified by the results of previous studies (e.g., Al-Hakim and Hassan 2013b; GarcíaSánchez et al. 2018; García-Morales et al. 2008). 
Empirical results also confirmed that the path between the LARG HRM and agile HRM has the highest value meaning that considering the agile paradigm has a considerable effect on HRM and is crucial for achieving the LARG HRM in the service sector. Concerning our results, organizations' employees tend to have easy access to the information and be more independent in performing their tasks (in groups or individually). Hence, managers should provide more freedom for the employees and pay more attention to their viewpoints in their decision-making process to enhance creativity among HR. Besides, green HRM, resilient HRM, and lean HRM have a relatively high path coefficient and play an essential role in achieving the LARG HRM. To successfully implement this concept, organizations should adequately understand all four paradigms of the LARG HRM concept. In this respect, the paradigm of lean by enhancing employees productivity and organizational performance by eliminating or minimizing operational time, the paradigm of resilience by improving organizational adaptability and future survival, even in the event of problems, and the paradigm of green by improving organizations ability to improve performance in environmentrelated issues are inseparable components of this concept.

Concerning the results, "employee's ability to perform several different jobs" (Q3) is the most effective criterion for the lean paradigm and greatly contributes to changing HR insight into lean thinking. Laying the ground for the training of employees to fulfill different tasks enables organizations to enjoy multifunctional expert employees. Such employees can fulfill tasks more efficiently. As a result, an employee can be an excellent substitute to perform the other employees' jobs. The presence of multifunctional employees in an organization significantly enhances the productivity and performance of the organization.

"Pay attention to employee's ideas in decision-making" (Q6) is another effective element in the implementation of the agile paradigm into the service sector. In today's pioneer organizations, employees exhibit their high decision-making capabilities once they face problems. It shows that managers no longer make important decisions in organizations, and employees play an important role in solving problems. In other words, managers can identify new capacities for their organizations by taking into account the ideas of their employees and providing them with higher freedom of action. Therefore, to benefit from HR with resilient thinking, "organization managers should adopt methods to increase the ability of their staff in changing rules or ways in different situations" (Q13). This flexibility helps HR make decisions quickly without wasting time in emerging problems and different situations. Given the results related to green HRM, "having employees with a full understanding of the extent of organization's environmental policies" (Q18) is the most crucial factor from the perspective of HR. In other words, realizing environmental issues by the staff is the first step in considering the green paradigm in the organization. Organizations with employees who have a comprehensive understanding of eco-friendly policies with an appropriate reward and compensation system associated with their eco-friendly behavior can be at the forefront of implementing the LARG HRM.

Despite the innovations in this study, there have been limitations that can be considered in future research. The results of this study are only significant in the service sector with a low response rate and can not necessarily be generalized to all industries. Independent research can be conducted in the same 
way in other industries such as healthcare and manufacturing with a higher number of respondents. Another potential venue for future research could be to examine the impact of different HR levels in the organization. Furthermore, since little research has investigated the lean, agile, resilient, and green paradigms in the HRM context, more empirical research is needed in to validate our results. Different variables such as knowledge management, organizational commitment, service quality, and job satisfaction can be added to the conceptual model of the research to evaluate their effects.

\section{Conclusions}

The present study investigates the paradigms of lean, agile, resilience, and green in HRM. A conceptual model is developed to analyze the impact of the LARG HRM on organizational performance with the mediation of organizational innovation. To the best of our knowledge, no study has been carried out to analyze the impact of LARG in the HRM context. In this way, we use structural equation modeling for analyzing the data obtained from questionnaires distributed among 210 organizational experts, senior experts, and managers. Based on the results, almost all lean, agile, resilient, and green items have substantial roles in implementing the LARG HRM. Furthermore, the LARG HRM affects organizational innovation and organizational performance significantly. In addition, there is a significant and positive relationship between organizational innovation and organizational performance. The results indicate that the top management of organizations should promote the LARG concept among their staff to improve their performances. The present study provides managers in organizations with a good insight into the implementation of the LARG HRM and how it contributes to the staff effectiveness to achieve higher organizational performance.

\section{Declarations}

\section{Author contribution}

All authors gave final approval and agree to be accountable for all aspects of the work, ensuring integrity and accuracy. All authors have made a substantial, direct, intellectual contribution to this study.

Authors' names: Nima Alipour (NA), Salman Nazari-Shirkouhi (SN), Mohamad Sadegh Sangari (MSS), Hadi Rezaei Vandchali (HRV)

Conception and design: NA, SN, MSS.

Design and implementation of software: NA, SN, MSS.

Acquisition of data: SN, HRV.

Analysis of data: NA, MSS.

Interpretation of data: SN, MSS. 
Drafting the manuscript: NA, SN, HRV.

Approval of the final version of the manuscript as submitted: NA and SN, MSS, HRV.

Funding None

Availability of data and materials All data and materials are available within the article and codes are available from the corresponding author on request

Ethical approval Not applicable.

Consent to participate Not applicable.

Consent to publish The authors agree with publish this paper in Environmental Science and Pollution Research

Competing interests The authors declare no conflict of interest

\section{References}

1. Agarwala T (2003) Innovative human resource practices and organizational commitment: An empirical investigation. International Journal of Human Resource Management 14(2):175-197

2. Ahmad S (2015) Green human resource management: policies and practices. Cogent Business \& Management 2(1):1030817

3. Al-Najjar B (2010) Corporate governance and institutional ownership: evidence from Jordan. Corporate Governance: The international Journal of Business in Society 10(2):176-190

4. Al-Hakim LAY, Hassan S (2013a) Knowledge management strategies, innovation, and organisational performance. Journal of Advances in Management Research 10(1):58-71

5. Al-Hakim LAY, Hassan S (2013b) Knowledge management strategies, innovation, and organisational performance: An empirical study of the Iraqi MTS. Journal of Advances in Management Research

6. Alipour N, Sangari MS, Nazari-Shirkouhi S (2019) Investigating green human resource practices in the healthcare sector: A joint application of balanced scorecard and SIR method. In 2019 15th Iran International Industrial Engineering Conference (IIIEC) IEEE, pp 283-288

7. Amjad F, Abbas W, Zia-Ur-Rehman M, Baig SA, Hashim M, Khan A, Rehman HU (2021) Effect of green human resource management practices on organizational sustainability: the mediating role of environmental and employee performance. Environ Sci Pollut Res 28(22):28191-28206

8. Azadeh A, Heydarian D, Nemati K, Yazdanparast R (2018) Performance optimization of unique resilient human resource management system in a coal mine industry. International Journal of System Assurance Engineering and Management 9(5):1178-1197

9. Azadeh A, Salehi V, Ashjari B, Saberi M (2014) Performance evaluation of integrated resilience engineering factors by data envelopment analysis: The case of a petrochemical plant. Process Saf 
Environ Prot 92(3):231-241

10. Azeem M, Ahmed M, Haider S, Sajjad M (2021) Expanding competitive advantage through organizational culture, knowledge sharing and organizational innovation. Technol Soc 66:101635

11. Azevedo SG, Carvalho H, Cruz-Machado V (2011) A proposal of LARG supply chain management practices and a performance measurement system. International Journal of e-Education e-Business e-Management and e-Learning 1(1):7

12. Azevedo SG, Carvalho H, Machado VC (2010) The influence of larg supply chain management practices on manufacturing supply chain performance context 3(25):26-27

13. Bamber GJ, Stanton P, Bartram T, Ballardie R (2014) Human resource management, Lean processes and outcomes for employees: towards a research agenda. International Journal of Human Resource Management 25(21):2881-2891

14. Bardoel EA, Pettit TM, De Cieri H, McMillan L (2014) Employee resilience: an emerging challenge for HRM. Asia Pacific Journal of Human Resources 52(3):279-297

15. Birmingham R, Bub K, Vaughn B (2017) Parenting in infancy and self-regulation in preschool: an investigation of the role of attachment history. Attach Hum Dev 19(2):107-129

16. Cabral I, Grilo A, Cruz-Machado V (2012) A decision-making model for lean, agile, resilient and green supply chain management. Int J Prod Res 50(17):4830-4845

17. Camisón C (1999) Sobre cómo medir las competencias distintivas: un examen empírico de la fiabilidad y validez de los modelos multi-item para la medición de los activos intangibles. In First International Conference of The Iberoamerican Academy of Management:"Management Related Theory and Research: An Iberoamerican Perspective, pp 9-11

18. Carvalho H, Cruz-Machado V (2011) Integrating lean, agile, resilience and green paradigms in supply chain management (LARG_SCM).Supply chain management27-48

19. Central Bank of the Islamic Republic of Iran (CBI) (2019) Annual National Accounts. (https://www.cbi.ir/simplelist/5796.aspx)

20. Chen CJ, Huang JW (2007) How organizational climate and structure affect knowledge management -The social interaction perspective. Int J Inf Manag 27(2):104-118

21. Chen L, Zheng W, Yang B, Bai S (2016) Transformational leadership, social capital and organizational innovation. Leadership \& Organization Development Journal 37(7):843-859

22. Chen Q, Wang CH, Huang SZ (2020) Effects of organizational innovation and technological innovation capabilities on firm performance: evidence from firms in China's Pearl River Delta Asia. Pacific Business Review 26(1):72-96

23. Chenhall RH (1997) Reliance on manufacturing performance measures, total quality management and organizational performance. Management Accounting Research 8(2):187-206

24. Chin TA, Tat HH, Sulaiman Z (2015) Green supply chain management, environmental collaboration and sustainability performance. Procedia CIRP 26:695-699 
25. Constantiou ID (2009) Consumer behaviour in the mobile telecommunications' market: The individual's adoption decision of innovative services. Telematics Inform 26(3):270-281

26. Correa H, Craft J (1999) Input-output analysis for organizational human resources management. Omega 27(1):87-99

27. da Silva César A, Conejero MA, Ribeiro ECB, Batalha MO (2019) Competitiveness analysis of "social soybeans" in biodiesel production in Brazil. Renewable Energy 133:1147-1157

28. Davadas SD, Lay YF (2017) Factors affecting students' attitude toward mathematics: A structural equation modeling approach. Eurasia Journal of Mathematics Science and Technology Education 14(1):517-529

29. Do BR, Yeh PW, Madsen J (2016) Exploring the relationship among human resource flexibility, organizational innovation and adaptability culture. Chinese Management Studies 10(4):657-674

30. Du Plessis M (2007) The role of knowledge management in innovation. Journal of knowledge management 8(04):317-330

31. Fay D, Shipton H, West MA, Patterson M (2015) Teamwork and organizational innovation: The moderating role of the HRM context. Creativity and Innovation Management 24(2):261-277

32. Fornell C, Larcker DF (1981) Evaluating structural equation models with unobservable variables and measurement error. J Mark Res 18(1):39-50

33. García-Sánchez E, García-Morales VJ, Martín-Rojas R (2018) Influence of technological assets on organizational performance through absorptive capacity, organizational innovation and internal labour flexibility. Sustainability 10(3):770

34. García-Morales VJ, Matías-Reche F, Hurtado-Torres N (2008) Influence of transformational leadership on organizational innovation and performance depending on the level of organizational learning in the pharmaceutical sector. Journal of Organizational Change Management 21(2):188212

35. Gligor DM, Esmark CL, Holcomb MC (2015) Performance outcomes of supply chain agility: when should you be agile? J Oper Manag 33:71-82

36. Govindan K, Azevedo SG, Carvalho H, Cruz-Machado V (2015) Lean, green and resilient practices influence on supply chain performance: interpretive structural modeling approach. Int J Environ Sci Technol 12(1):15-34

37. Guest DE (1997) Human resource management and performance: a review and research agenda. International journal of human resource management 8(3):263-276

38. Guest DE, Paauwe J, Wright P (2012) HRM and performance: Achievements and challenges. John Wiley \& Sons

39. Gunday G, Ulusoy G, Kilic K, Alpkan L (2011) Effects of innovation types on firm performance. Int J Prod Econ 133(2):662-676

40. Hair J, Black W, Babin B, Anderson R, Tatham R (2010) Multivariate data analysis Upper Saddle River. Pearson Prentice Hall 
41. Hair JF, Ringle CM, Sarstedt M (2011) PLS-SEM: Indeed a silver bullet. Journal of Marketing theory and Practice 19(2):139-152

42. Henard DH, Szymanski DM (2001) Why some new products are more successful than others. J Mark Res 38(3):362-375

43. Henseler J, Ringle CM, Sinkovics RR (2009) The use of partial least squares path modeling in international marketing. In New challenges to international marketing. Emerald Group Publishing Limited

44. Henseler J, Sarstedt M (2013) Goodness-of-fit indices for partial least squares path modeling. Comput Stat 28(2):565-580

45. Holtom BC, Mitchell TR, Lee TW, Eberly MB (2008) 5 turnover and retention research: a glance at the past, a closer review of the present, and a venture into the future. Acad Manag Ann 2(1):231-274

46. Hsiao TY, Chuang CM, Kuo NW, Yu SMF (2014) Establishing attributes of an environmental management system for green hotel evaluation. International Journal of Hospitality Management 36:197-208

47. Hu D, Wang Y, Huang J, Huang H (2017) How do different innovation forms mediate the relationship between environmental regulation and performance? J Clean Prod 161:466-476

48. Jiang J, Wang S, Zhao S (2012) Does HRM facilitate employee creativity and organizational innovation? A study of Chinese firms. The International Journal of Human Resource Management 23(19):4025-4047

49. Jimenez-Jimenez D, Sanz-Valle R (2005) Innovation and human resource management fit: an empirical study. Int J Manpow 26(4):364-381

50. Jimenez-Jimenez D, Sanz-Valle R (2008) Could HRM support organizational innovation? The International Journal of Human Resource Management 19(7):1208-1221

51. Jiménez DJ, Valle RS (2006) Innovación, aprendizaje organizativo y resultados empresariales: un estudio empírico.Cuadernos de Economía y Dirección de la Empresa(29):31-55

52. Katou AA (2012) Investigating reverse causality between human resource management policies and organizational performance in small firms. Management Research Review 35(2):134-156

53. Katou AA (2015) The mediating effects of psychological contracts on the relationship between human resource management systems and organisational performance. Int J Manpow 36(7):10121033

54. Katou AA (2017) How does human resource management influence organisational performance? An integrative approach-based analysis. International Journal of Productivity and Performance Management 66(6):797-821

55. Ketkar S, Sett P (2009) HR flexibility and firm performance: Analysis of a multi-level causal model. The International Journal of Human Resource Management 20(5):1009-1038

56. Khan SAR, Qianli D (2017) Impact of green supply chain management practices on firms' performance: an empirical study from the perspective of Pakistan. Environ Sci Pollut Res 
24(20):16829-16844

57. Khatri N (2000) Managing human resource for competitive advantage: a study of companies in Singapore. International Journal of Human Resource Management 11(2):336-365

58. Kossek EE, Perrigino MB (2016) Resilience: A review using a grounded integrated occupational approach. The Academy of Management Annals 10(1):729-797

59. Lambooij M, Sanders K, Koster F, Zwiers M (2006) Human Resource Practices and Organisational Performance: Can the HRM-performance linkage be explained by the cooperative behaviours of employees? Management revue 17(3):223-240

60. Lee JS, Hsieh CJ (2010) A research in relating entrepreneurship, marketing capability, innovative capability and sustained competitive advantage. Journal of Business \& Economics Research 8(9):109-119

61. Lee KW, Tsai MT, Lanting MCL (2011) From marketplace to marketspace: Investigating the consumer switch to online banking. Electron Commer Res Appl 10(1):115-125

62. Li S, Ragu-Nathan B, Ragu-Nathan T, Rao SS (2006) The impact of supply chain management practices on competitive advantage and organizational performance. Omega 34(2):107-124

63. Lu CM, Chen SJ, Huang PC, Chien JC (2015) Effect of diversity on human resource management and organizational performance. J Bus Res 68(4):857-861

64. Lyskova I, Rudakova O (2020) Agile Management as a Technology of Professional Development of the Human Resources in a Credit Organization. In 5th International Conference on Economics, Management, Law and Education (EMLE 2019), 405-409, Atlantis Press

65. Machado VC, Duarte S (2010) Tradeoffs among paradigms in supply chain management. In International Conference on Industrial Engineering and Operations Management, pp 9-10

66. Maheshwari S, Vohra V (2015) Identifying critical HR practices impacting employee perception and commitment during organizational change. Journal of Organizational Change Management

67. Mak SK, Akhtar S (2003) Human resource management practices, strategic orientations, and company performance: a correlation study of publicly listed companies. Journal of American Academy of Business 2(2):510-515

68. Maletič M, Maletič D, Dahlgaard JJ, Dahlgaard-Park SM, Gomišček B (2014) The Relationship between Sustainability- Oriented Innovation Practices and Organizational Performance: Empirical Evidence from Slovenian Organizations. Organizacija 47(1):3-13

69. Mathapati C (2013) Green HRM: A strategic facet. Tactful Management Research Journal 2(2):1-6

70. Mosavi SM, Sangari MS, Keramati A (2018) An integrative framework for customer switching behavior. Serv Ind J 38(15-16):1067-1094

71. Nawanir G, Lim KT, Othman SN, Adeleke AQ (2018) Developing and validating lean manufacturing constructs: an SEM approach. Benchmarking: An International Journal 25(5):1382-1405

72. Nikbin D, Marimuthu M, Hyun SS (2016) Influence of perceived service fairness on relationship quality and switching intention: An empirical study of restaurant experiences. Current Issues in 
Tourism 19(10):1005-1026

73. Nunnally JC (1978) Psychometric Theory, 2nd edn. In: Mcgraw hill book company

74. Orhan A, Kirikkaleli D, Ayhan F (2019) Analysis of wavelet coherence: service sector index and economic growth in an emerging market. Sustainability 11(23):6684

75. Ostraszewska Z, Tylec A, Vasylyk S (2019) The role of human resources in the creation of innovation position of Poland-comparative analysis to EU countries based on SII index. System Safety: HumanTechnical Facility-Environment 1(1):902-911

76. Paauwe J, Boselie P (2005) HRM and performance: what next? Human resource management journal 15(4):68-83

77. Parker C (2000) Performance measurement. Work study

78. Prajogo DI, Ahmed PK (2006) Relationships between innovation stimulus, innovation capacity, and innovation performance. R\&D Management 36(5):499-515

79. Rachid B (2017) Supply chain improvement in LARG (Lean, Agile, Resilient, Green) context: A Risk Management Approach. In 2017 6th IEEE International Conference on Advanced Logistics and Transport (ICALT), pp 212-220

80. Raut RD, Mangla SK, Narwane VS, Dora M, Liu M (2021) Big Data Analytics as a mediator in Lean, Agile, Resilient, and Green (LARG) practices effects on sustainable supply chains. Transp Res $E$ 145:102170

81. Rehman SU, Mohamed R, Ayoup H (2019) The mediating role of organizational capabilities between organizational performance and its determinants. Journal of Global Entrepreneurship Research $9(1): 30$

82. Safkaur O, Sagrim Y (2019) Impact of Human Resources Development on Organizational Financial Performance and Its Impact on Good Government Governance. International Journal of Economics and Financial Issues 9(5):29

83. Salleh NHM, Abd Rasidi NAS, Jeevan J (2020) Lean, agile, resilience and green (LARG) paradigm in supply chain operations: a trial in a seaport system. Australian Journal of Maritime \& Ocean Affairs 12(4):200-216

84. Sangari MS, Razmi J (2015) Business intelligence competence, agile capabilities, and agile performance in supply chain. The International Journal of Logistics Management 26(2):356-380

85. Schuler R, Jackson S (2014) Human resource management and organizational effectiveness: yesterday and today. Journal of Organizational Effectiveness: People and Performance 1(1):35-55

86. Sharifi H, Zhang Z (1999) A methodology for achieving agility in manufacturing organisations: An introduction. Int J Prod Econ 62(1-2):7-22

87. Shaukat S, Nawaz MS, Naz S (2013) Effects of innovation types on firm performance: An empirical study on Pakistan's manufacturing sector. Pakistan Journal of Commerce and Social Sciences (PJCSS) 7(2):243-262 
88. Skibiński A, Sipa M (2015) Sources of innovation of small businesses: Polish perspective. Procedia Economics and Finance 27:429-437

89. Su MF, Cheng KC, Chung SH, Chen DF (2018) Innovation capability configuration and its influence on the relationship between perceived innovation requirement and organizational performance:

Evidence from IT manufacturing companies. Journal of Manufacturing Technology Management 29(8):1316-1331

90. Temme D, Kreis H, Hildebrandt L (2010) A comparison of current PLS path modeling software: Features, ease-of-use, and performance. In Handbook of partial least squares 737-756

91. Uzkurt C, Kumar R, Kimzan HS, Eminoğlu G (2013) Role of innovation in the relationship between organizational culture and firm performance. European Journal of Innovation Management 16(1):92-117

92. Vaňová A, Šúrová J, Seková M (2019) Human resources and competitiveness of the territory. Acta Academica Karviniensia 19(1):106-118

93. Vilkas M, Rauleckas R, Šeinauskienè B, Rutelionė A (2019) Lean, Agile and Service-oriented performers: templates of organising in a global production field Total Quality Management \& Business Excellence 1-25

94. Yu MM, Chern CC, Hsiao B (2013) Human resource rightsizing using centralized data envelopment analysis: Evidence from Taiwan's. Airports Omega 41(1):119-130

95. Zhu Q, Sarkis J, LAI KH (2008) Confirmation of a measurement model for green supply chain management practices implementation. Int J Prod Econ 111(2):261-273

\section{Figures}




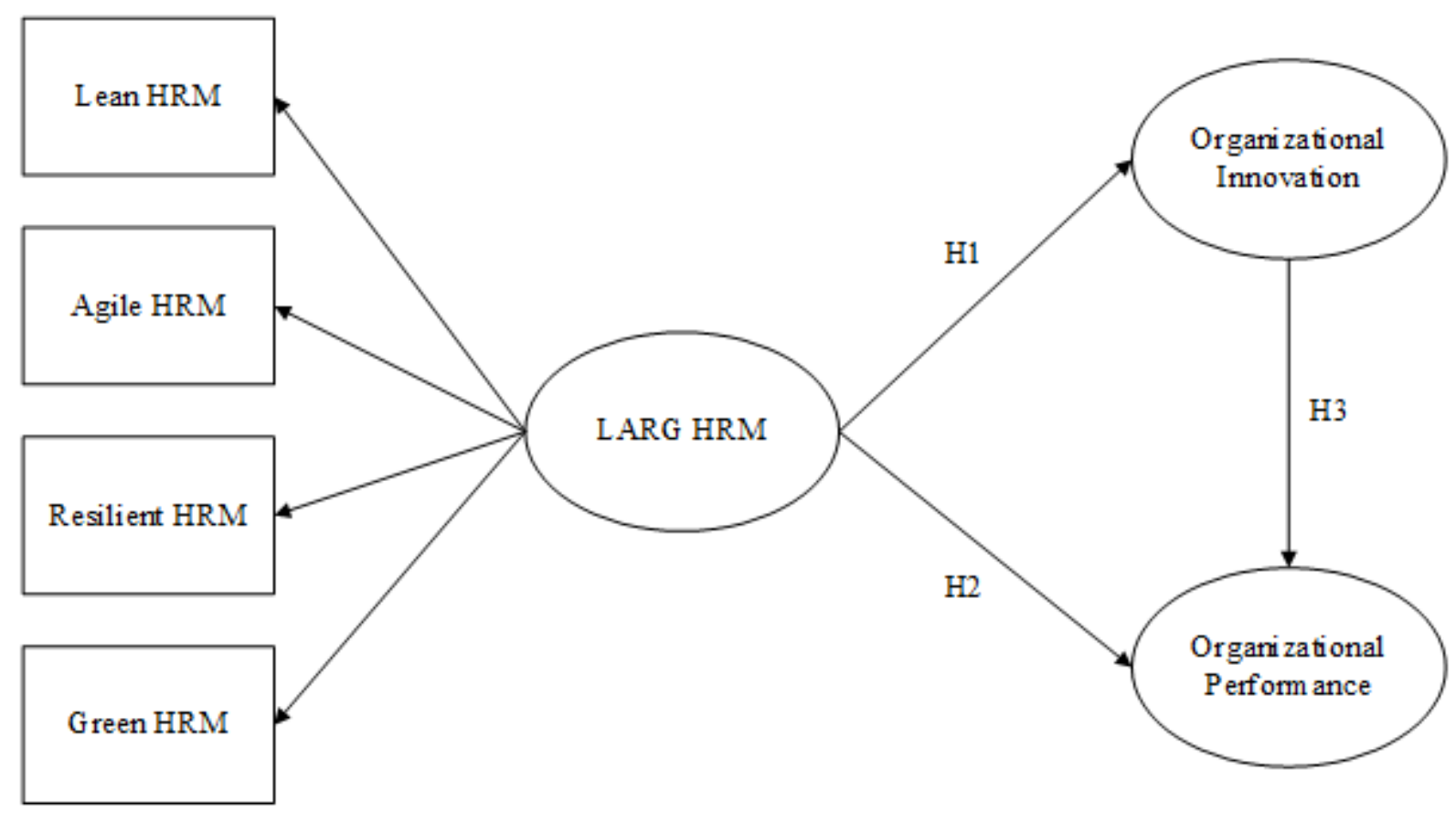

Figure 1

Research model

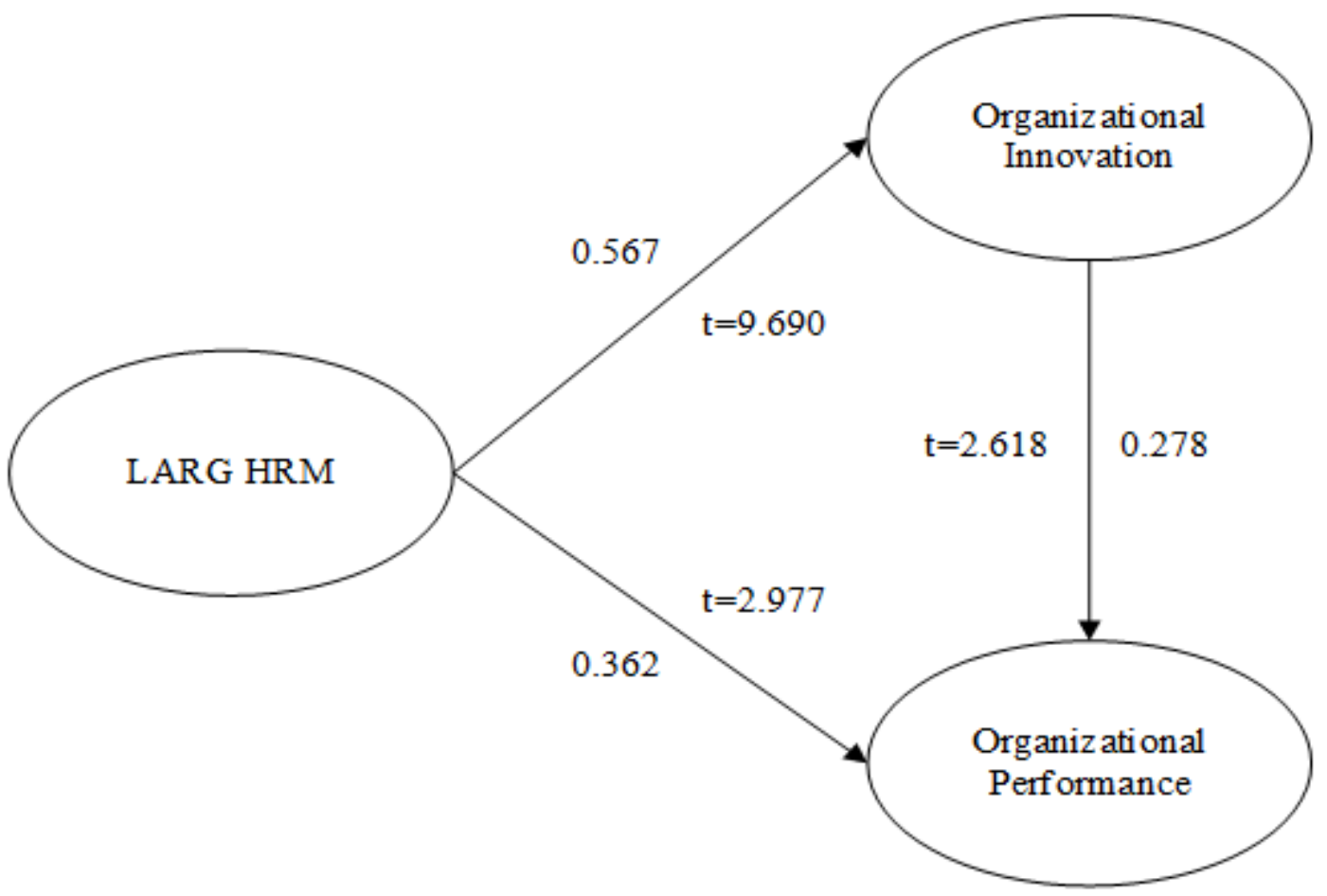

Figure 2 
Results of path analysis

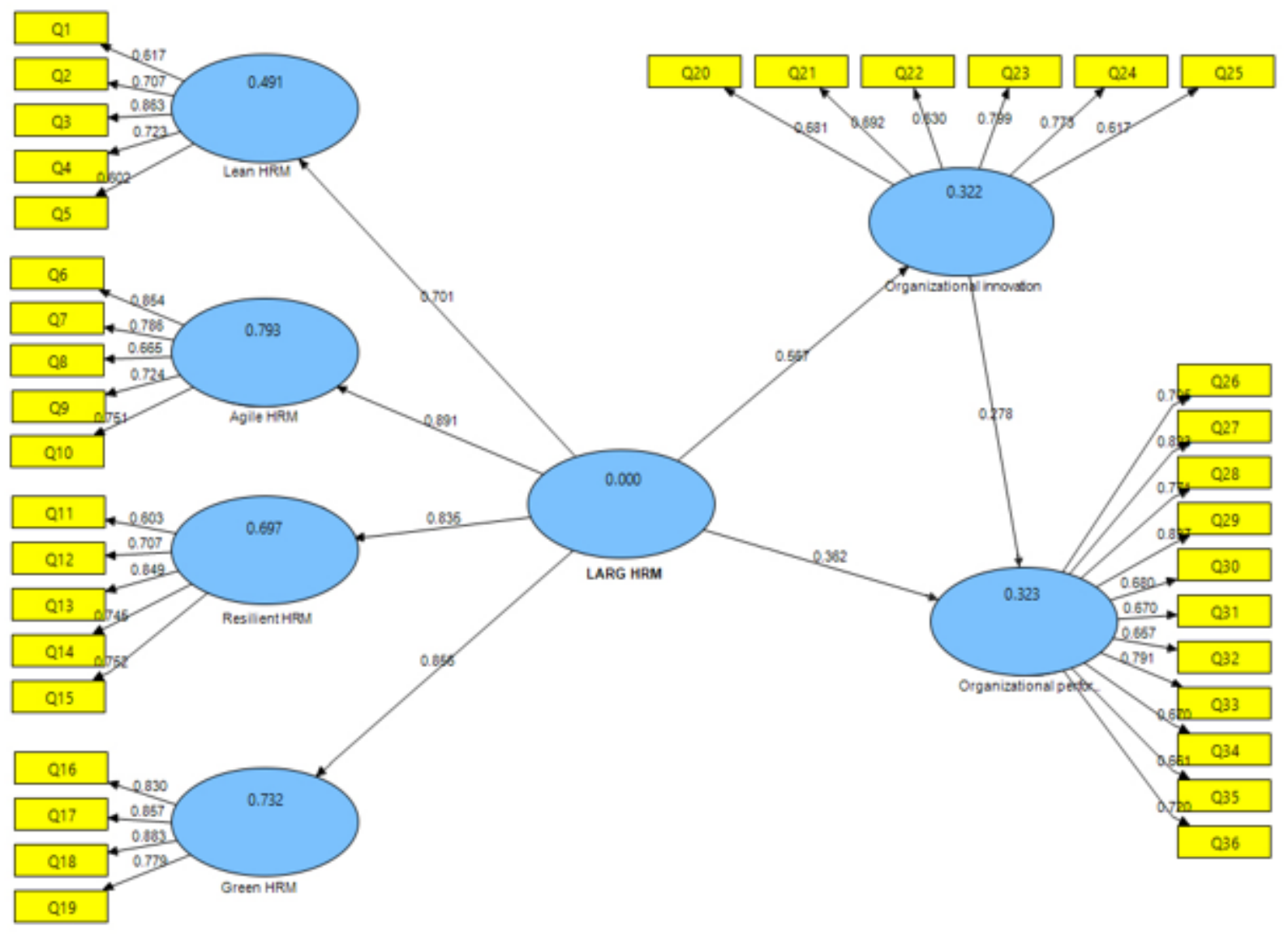

Figure 3

Results of path analysis

\section{Supplementary Files}

This is a list of supplementary files associated with this preprint. Click to download.

- AppendixA.docx 